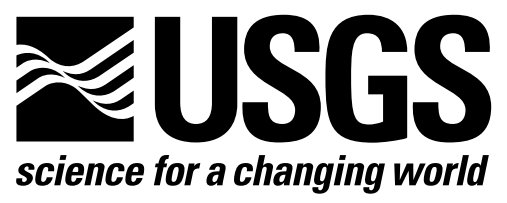

\title{
GPS-aided Inertial Technology and Navigation- based Photogrammetry for Aerial Mapping the San Andreas Fault System
}

By Richard D. Sanchez'; Kenneth W. Hudnut ${ }^{2}$

Open-File Report 2004-1389

'Eastern Region Geography, Regional Investigations Team, Reston, VA 20192

${ }^{2}$ Western Region Geology, Earthquake Hazards Team, Pasadena, CA 91106

U.S. Department of the Interior

U.S. Geological Survey 


\title{
GPS-aided Inertial Technology and Navigation-based Photogrammetry for Aerial Mapping the San Andreas Fault System
}

\author{
Richard D. Sanchez \\ U.S. Geological Survey \\ Reston, VA 20192
}

\author{
Kenneth W. Hudnut \\ U.S. Geological Survey \\ Pasadena, CA 91125
}

\begin{abstract}
Aerial mapping of the San Andreas Fault System can be realized more efficiently and rapidly without ground control and conventional aerotriangulation. This is achieved by the direct geopositioning of the exterior orientation of a digital imaging sensor by use of an integrated Global Positioning System (GPS) receiver and an Inertial Navigation System (INS). A crucial issue to this particular type of aerial mapping is the accuracy, scale, consistency, and speed achievable by such a system. To address these questions, an Applanix Digital Sensor System (DSS) was used to examine its potential for near realtime mapping. Large segments of vegetation along the San Andreas and Cucamonga faults near the foothills of the San Bernardino and San Gabriel Mountains were burned to the ground in the California wildfires of October-November 2003. A $175 \mathrm{~km}$ corridor through what once was a thickly vegetated and hidden fault surface was chosen for this study. Both faults pose a major hazard to the greater Los Angeles metropolitan area and a near real-time mapping system could provide information vital to a post-disaster response.
\end{abstract}

\section{Introduction}

Today there are three generally accepted methods to geoposition airborne or remotely sensed images to a local or national mapping frame of reference. The conventional method is completely dependent on well-distributed photo-identifiable geodetic ground control points and aerotriangulation. The second method combines airborne integrated GPS/INS collected data and a lesser number of ground control points with assisted aerotriangulation (Colomina, 2000). The latter method, which was chosen for this pilot study, is completely dependent on airborne GPS-aided inertial navigation systems to identify the location and orientation of each aerial image at the time of exposure.

Over the years many airborne integrated GPS/INS performance tests of have been conducted (Cramer, 1999; Cramer, Stallmann, and Haala, 2000). Many of these tests were flown over flat terrain and successfully met positional accuracy standards for largescale mapping. However, tests flown over steep terrain, for the most part, have not met mapping accuracy standards at better than 1:8,000-scale (Cramer, 1999; Greening and others, 2000; Sanchez and Hothem, 2002; and Sanchez, 2004). The approach employed in this pilot study will first test a newly installed Applanix Digital Sensor System (DSS)

Any use of trade, product, or firm names is for descriptive purposes only and does not imply endorsement by the U.S. Government 
2.5 second cycle chip to attain an image pixel resolution of $8-15 \mathrm{~cm}(3-6$ inches $)$; and second apply carrier phase differential Global Positioning System (DGPS) postprocessing using multiple base stations of the Southern California Integrated GPS Network (Hudnut et al., 2002), to achieve a horizontal and vertical positional accuracy of less than $15 \mathrm{~cm}$. A number of studies have shown significant accuracy improvements when operating in a multi-receiver configuration (Shi, 1994, Raquet, 1998, Bruton, Mostafa, and Scherzinger, 2001). Reaching these higher resolution and accuracy goals will demonstrate the potential of airborne integrated GPS/INS for the near real-time mapping of the San Andreas Fault System, thus, enabling information vital to postearthquake disaster response and damage assessment.

\section{Pilot Test Area}

The San Andreas and Cucamonga fault segments in the vicinity of San Bernardino, California, were selected for the pilot test. The fault segments which lie along the foothills of the San Bernardino Mountains were in the path of the wildfires of October 2003 (figure 1). The surface topography is a rough succession of canyons, slopes and valleys carved out by arroyos and washes (inset, figure 1). These wildfires, although undesirable, created a window of opportunity to map these once obscure vegetated fault surfaces.

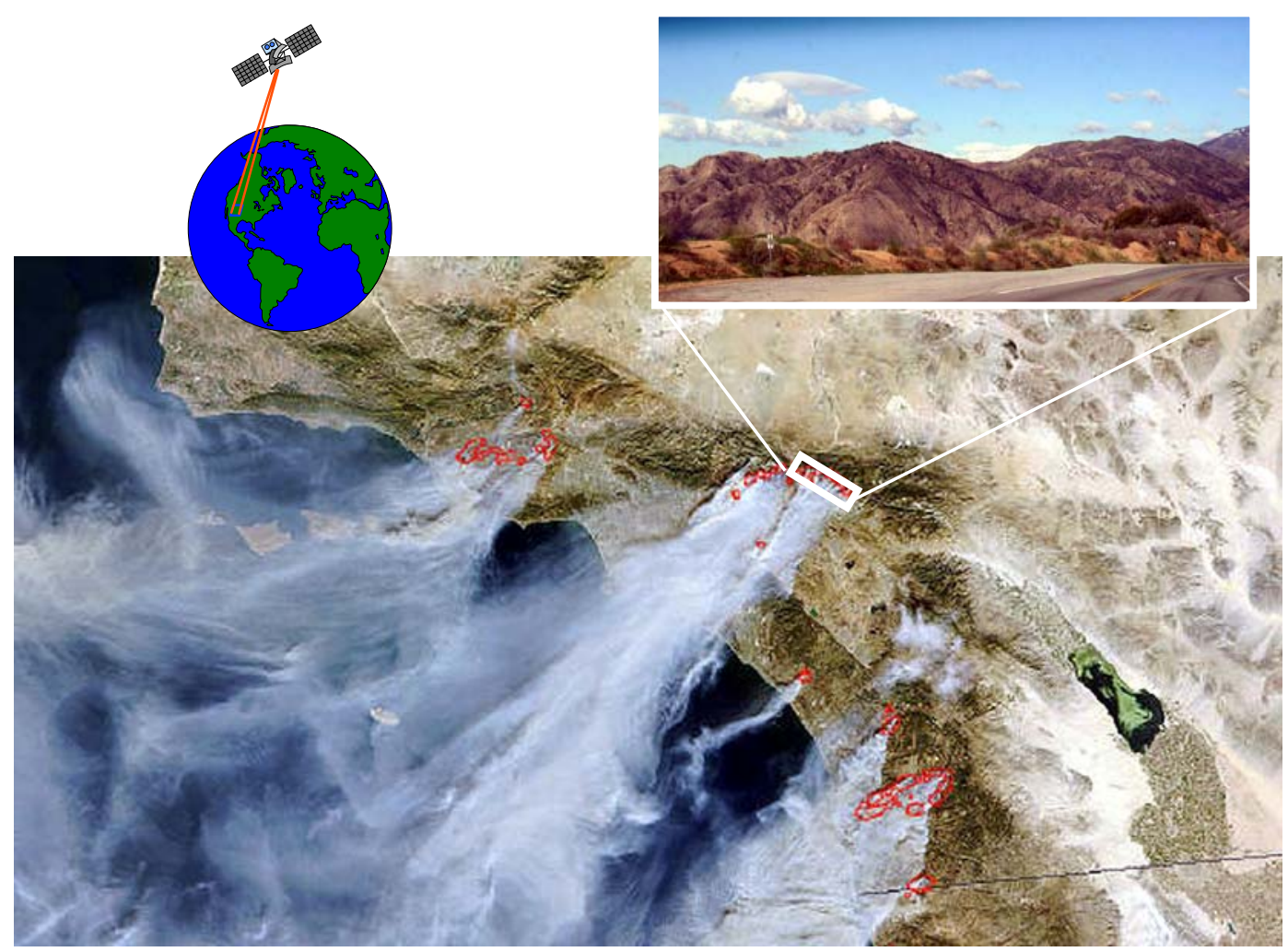

Figure1. Satellite view of the 2003 Southern California wildfires and pilot test area. 


\section{System Configuration, Calibration, and Reference Stations}

The commercial airborne integrated GPS/INS used in this project is the DSS and the Position and Orientation System for Aerial Vehicle (POS AV) 410 package from Applanix Corp., Ontario, Canada (Trimble is the parent company of Applanix Corporation). The DSS camera is a medium format sensor with a $55.01 \mathrm{~mm}$ focal length and $4 \mathrm{k} \mathrm{x} 4 \mathrm{k}$ pixel array. Each color image is digitally exposed every 2.5 seconds in three bands (red, green, and blue) with a base/height ratio of $0.5-1.0$. The Applanix POS AV 410 for Direct Georeferencing (DG) package comprises four main components: (1) a dual-frequency L1/L2 carrier phase embedded GPS receiver (NovAtel MiLLennium), (2) a POS Inertial Measurement Unit (Litton LR-86), (3) the POS computer system, and (4) the POSPac post-processing software (comprised of POSRT, POSGPS, POSPROC, and POSEO modules). For the test, the DSS was rigidly mounted in the Applanix's Cessna 182 aircraft (figure 2). The GPS antenna was centered above the camera on top of the fuselage of the aircraft - the horizontal offset of the antenna phase center was very small and treated as zero.

According to Gerald Kinn of the Applanix Corporation, the individual sensor calibration of the DSS was done in the Applanix Lab and the overall systems calibration of the antenna, camera, and inertial measurement unit (IMU) lever arms, and the IMU/camera boresight, were carried out by Applanix at their Florida test range. To resolve any boresight transformation, Applanix compares the GPS/IMU positioning/orientation results with the aerial triangulation solution, then used the data from the POSEO and aerial triangulation from the flight to resolve any fixed misalignment angles between the IMU and the camera. "Event markers are recorded during the aerial survey to precisely identify shutter release times for frame cameras. These event markers are extracted during post-processing." (Applanix website at http://www.applanix.com).

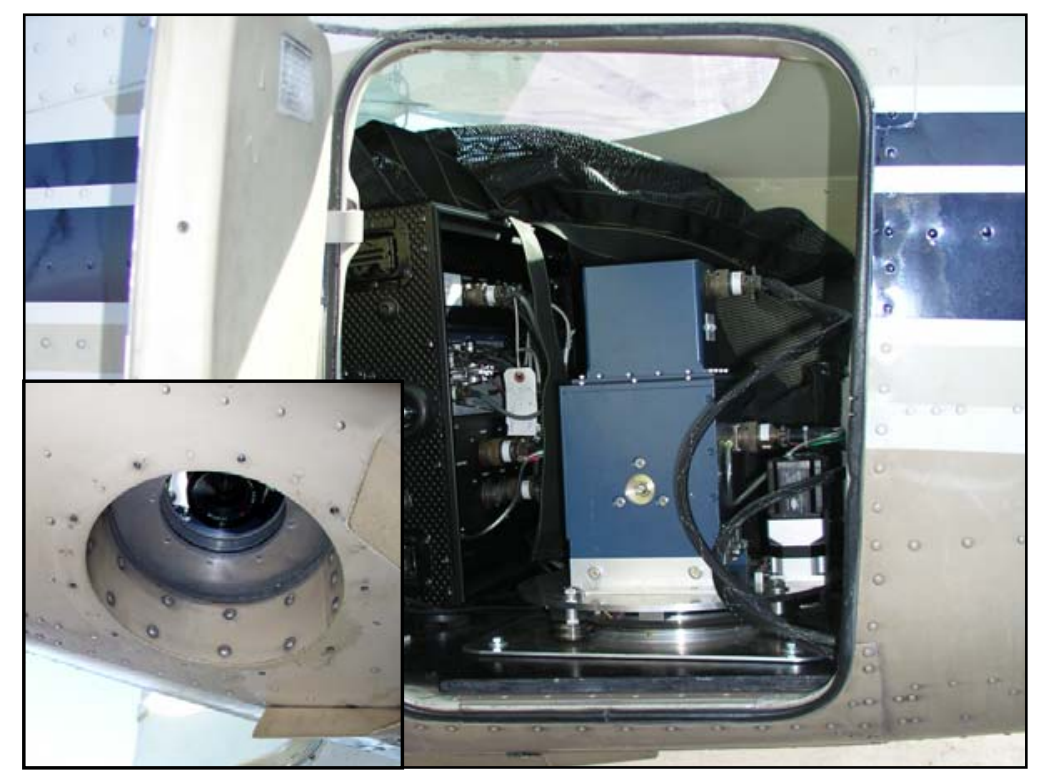

Figure 2. View of mounted DSS and inset of camera port hole under the aircraft. 
Five continuous Southern California Integrated GPS Network (SCIGN) operating reference sites (http://www.scign.org/) provided the multiple base stations used in combination with carrier phase DGPS post-processing to achieve optimum accuracy. The SCIGN reference station data were processed in conjunction with the airborne GPS raw observables to determine the aircraft position which was then used to aid the inertial data processing in a closed loop manner to end up with a full resolution of the trajectory parameters, namely position, velocity, and attitude which were then used to generate exterior orientation data to support aerial mapping.

Aerial panels were setup over existing benchmarks throughout the project corridor by the San Bernardino County Surveyor's office. These panels provided valuable ground control points (GCPs) for the photogrammetric test measurement of position and height.

\section{Position and Orientation Solution}

The over-flight of the project corridor was carried out on March 16, 17 and 18, 2004, under clear skies and windy flying conditions at altitudes of 457 to 2,896 meters $(1,500$ to 9,500 ft). As shown in figure 3, five well distributed SCIGN stations (TABL, CJMS, EWPP, CRFP, and BBRY) were chosen to support the multiple reference base station solution approach. Stations TABL, CJMS, EWPP, and CRFP range between 3 to $6 \mathrm{~km}$

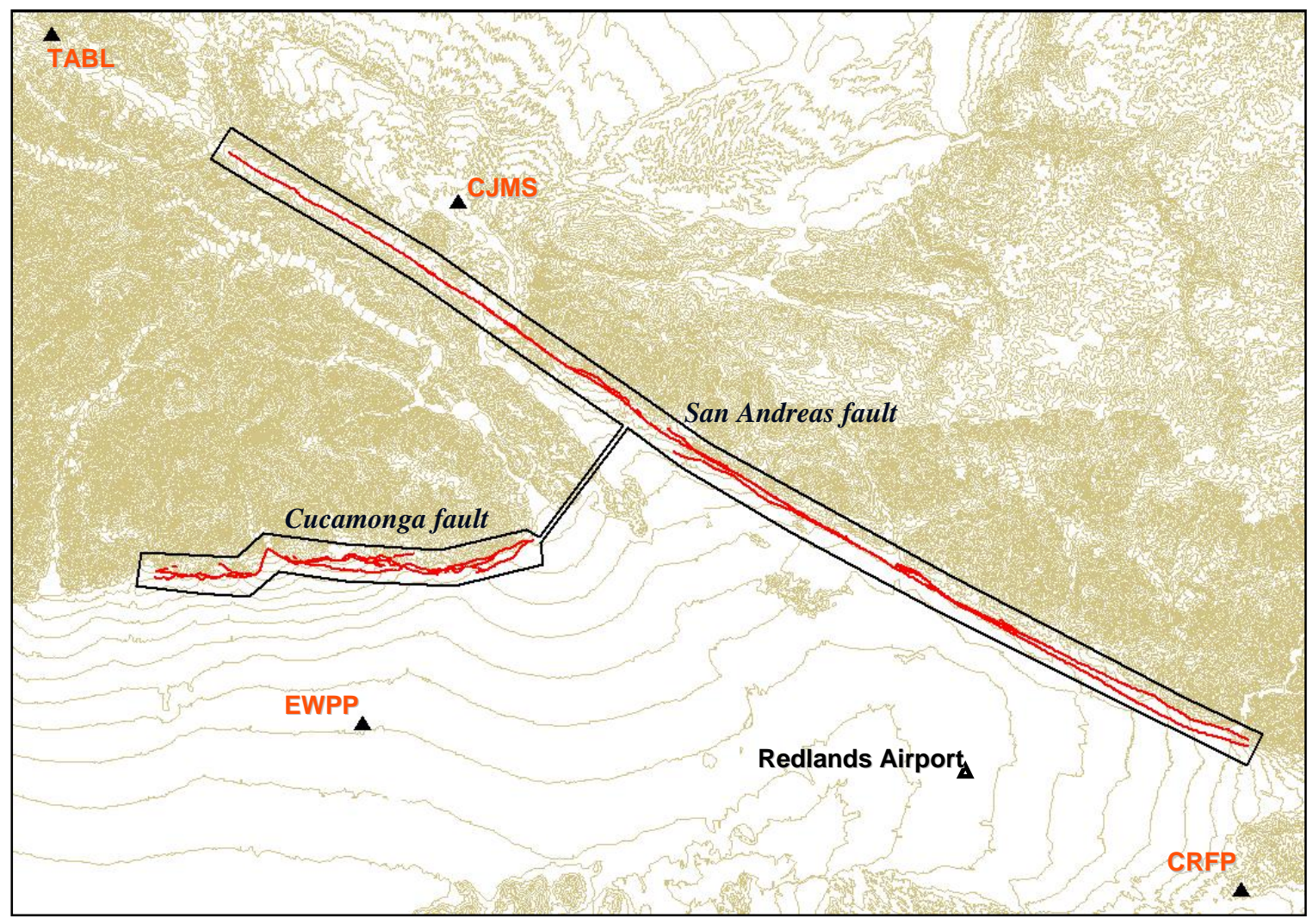

Figure 3. The flight corridor and location of the reference base stations. 
from the project corridor. The BBRY station is situated $23 \mathrm{~km}$ northeast of the corridor (off the map in figure 3). These selected SCIGN stations operated at a data collection rate of 1 -second intervals during the entire period. In addition, a single dedicated base station was set up and operated by Applanix at the Redlands Airport, $6 \mathrm{~km}$ from the southeastern track of the San Andreas fault corridor.

Using Applanix POSGPS post-processing module, GPS raw carrier phase data from all five SCIGN stations were used in the carrier phase differential GPS solutions. All five base stations were used as input in the computation of the trajectory and attitude of the DSS to combine the coordinate and orientation results from each SCIGN station in a weighted average approach. The well distributed SCIGN stations provided a geometrically strong solution yielding a composite position closer to the aircraft than the single Redland Airport station. The separation between the SCIGN composite position and the aircraft at anytime varied from 3 to $23 \mathrm{~km}$, while the Redlands Airport single base station distance to the aircraft ranged from 6 to $42 \mathrm{~km}$. The multiple reference station carrier phase post-processing enables the reduction of the effects of reference station noise and multipath, and GPS error spatial decorrelation which is the major error source of a single reference station. The standard single reference station DGPS involves amplification of the user range noise with the reference station range noise because of the differencing process (Lachapelle, 1991). This noise amplification is minimized by the averaging process when using multiple reference carrier phase DGPS solution. The reference stations together with the airborne GPS carrier phase data provided the navigation solutions (multiple and single) to compute the camera coordinates and exterior orientation angles in the local mapping frame, at camera exposure time.

In comparing the GCP coordinates and their corresponding panel points in the stereo models (derived from the exterior orientation parameters of each solution), the average positional offset of the single solution was: $-2.33 \mathrm{~m}$ (delta $\mathrm{x}$ ), $-1.56 \mathrm{~m}$ (delta $\mathrm{y}$ ), and +7.81 $\mathrm{m}$ (delta vertical). See tables 1 and 2 for the average positional offset of the multiple reference station solution.

\section{Navigation-based Photogrammetry and Ground Truthing}

These Applanix POSEO derived camera perspective center coordinates (easting, northing, and elevation in Earth Centered Earth Fixed frame of reference) and the camera orientation parameters (in angles omega, phi, kappa, $\omega, \Phi, \kappa$ ), as well as the camera's internal geometry and lens characteristics, were applied by the U.S. Geological Survey (USGS) to geometrically correct the digital aerial frames using the Softcopy Exploitation Tool Set (SOCET Set) photogrammetric software (SOCET Set ${ }^{\circledR}$ is a trademark of BAE Systems Solutions, Inc.). Unlike the conventional photogrammetric procedure where ground control and aerotriangulation are required to create an exterior orientation file, in navigation-based photogrammetry the POSEO file is used to generate the stereo models. Figure 4 charts the course of the navigation-based photogrammetric process. A workaround solution was developed by BAE and the author to permit the direct importation of the POSEO data in text file format. The POSEO file is currently imported by "Multi- 
Sensor Triangulation" menu option in the SOCET Set 5.1 version. Future versions will permit a more direct method through the Frame Import menu where in the Review/Edit Setting window one can enable Camera Position/Orientation and select "Read from file"

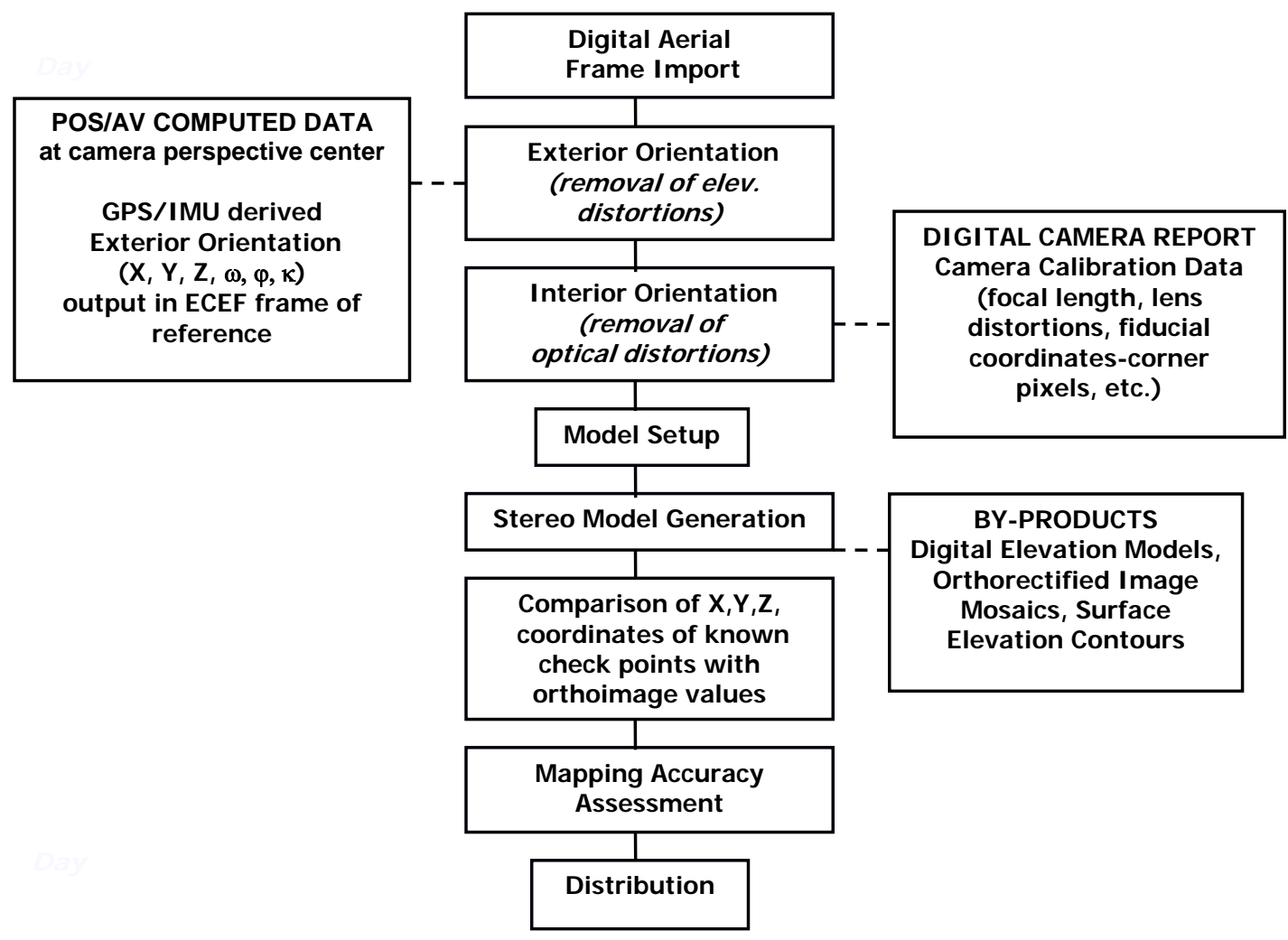

Figure 4. Flow chart of the navigation-based photogrammetric process used in this study.

button and click and enter the POSEO.txt file to import all the frames. If a batch file is unavailable or incompatible, a more laborious procedure is to either manually enter the data for each frame or cut-and-paste a text file from the POSEO data (the naming convention for the image files and POSEO file must be the same). A total of 1,446 color image frames were collected over the test site. Three-band color image derived products were generated with SOCET Set in UTM coordinates system, ITRF 2002 datum, GRS 1980 ellipsoid heights, and meter units. (See example of the color image in figure 5).

To know the grid coordinate of any point in the project area, aerial panels were positioned over benchmarks set by the San Bernardino County Surveyor's office along the San Andreas and Cucamonga faults before the flight missions took place (figure 5). The panel grid coordinates were determined by the San Bernardino County Surveyor's office using kinematic GPS surveying. These panel coordinates provided the initial accuracy measurement of the horizontal position and height (figure 6). However, to obtain accurate coordinates of these panels, static surveys were conducted by the USGS. Seven of these panel points were occupied for less than 30 minutes at five second intervals using Ashtech Z-12 receivers. The simultaneous collection from the SCIGN continuous operating reference stations at one second intervals provided the RINEX files 


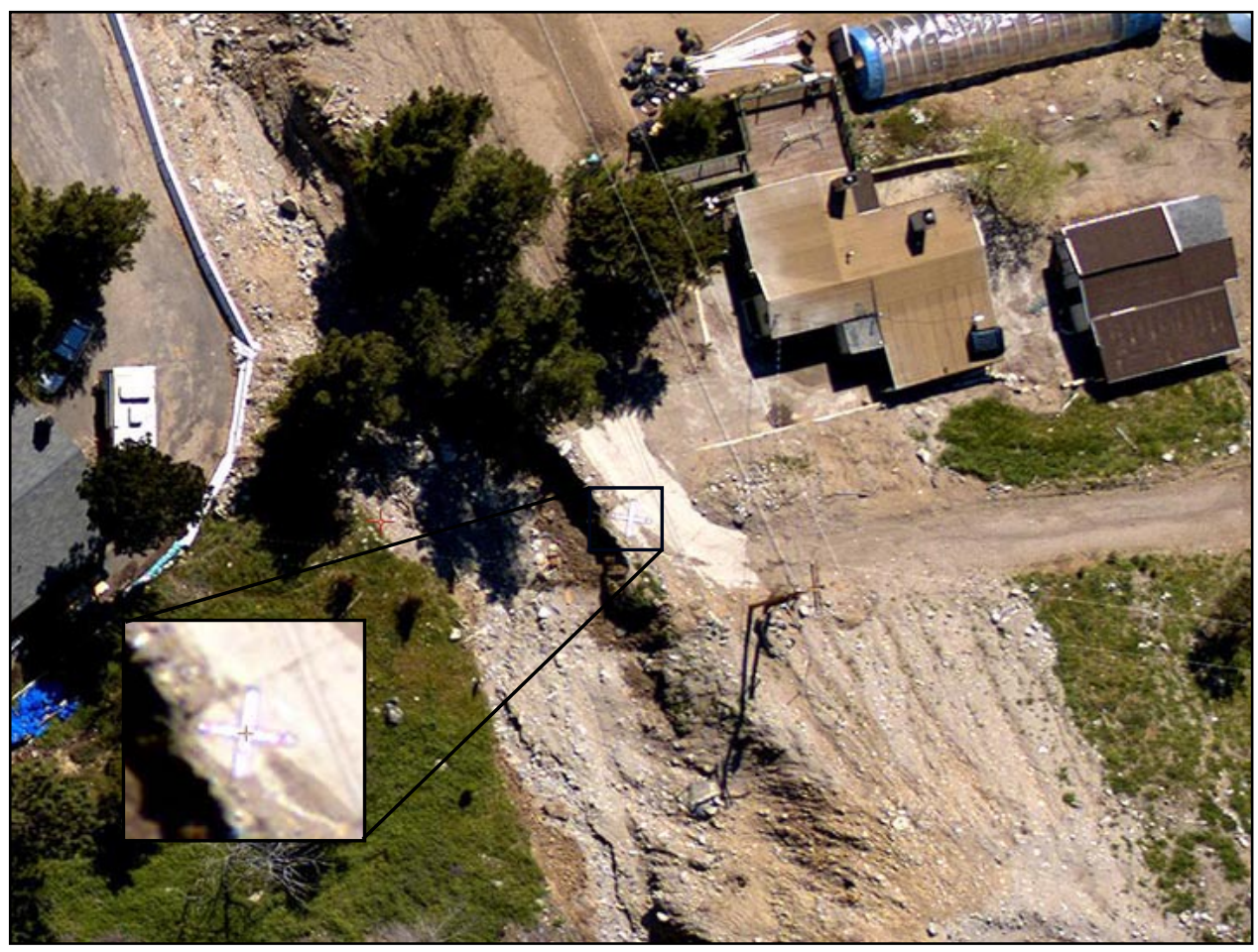

Figure 5. Color image derived from DSS data showing County aerial panel.

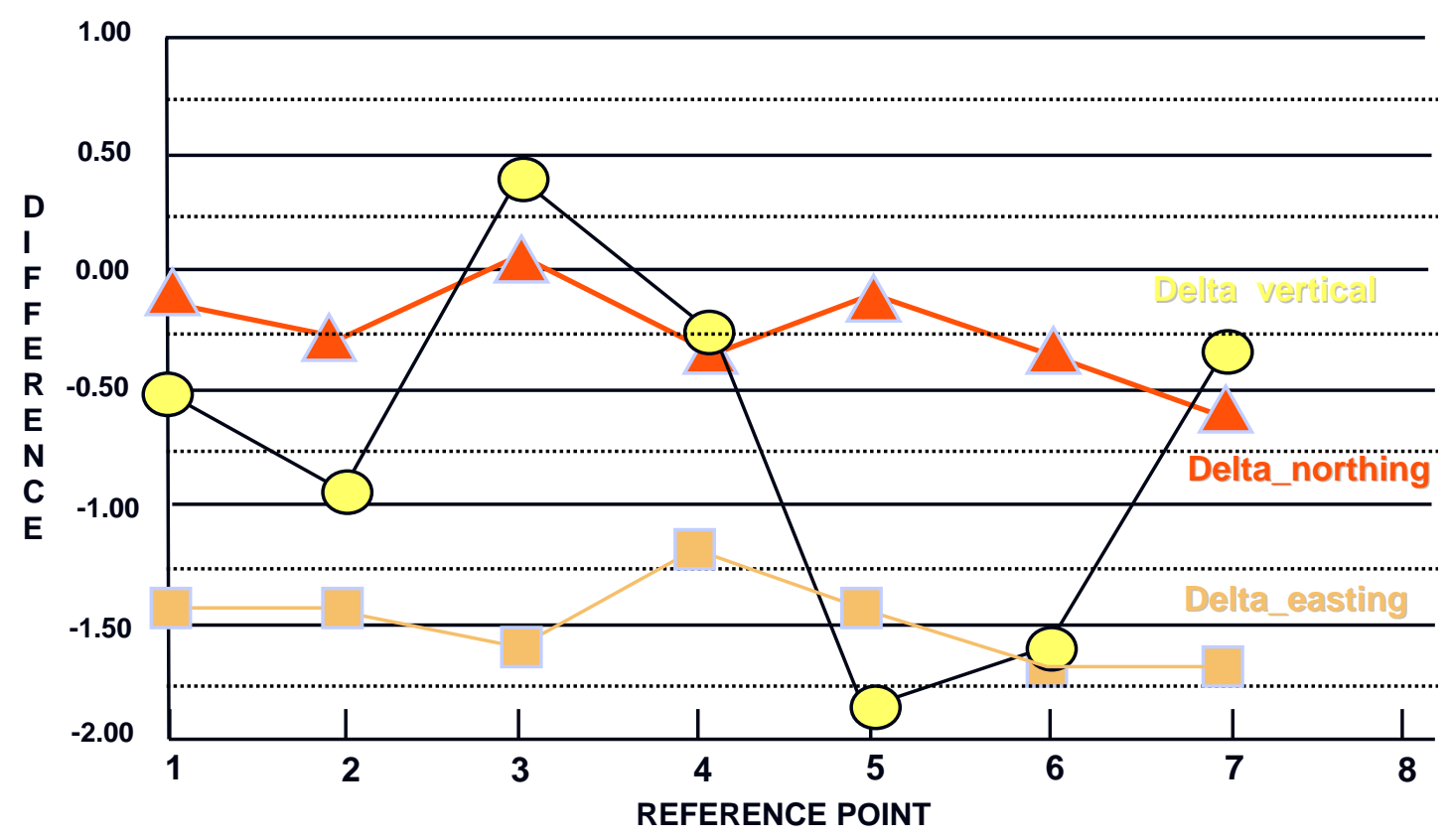

Figure 6. Graphic illustration of the difference between the San Bernardino County kinematic-surveyed panel coordinates and their corresponding panel position coordinates measured on the digital photogrammetric workstation, in meters. 
(range and carrier phase or binary measurements, predicted orbital coordinates or ephemeris data, and site information files) used in the post-processing with Ashtech Solutions Version 2.5. Traditional setup (adjustable tripod) of the antenna over the benchmarks was used in these static surveys.

\section{Positional Accuracy Analysis}

Absolute orientation was examined using the horizontal and vertical coordinates of the visible panel points in the stereo models and the values of their corresponding surveyed positions on the ground. The difference between the logged surveyed panel coordinates and corresponding panel points displayed in the stereoimage were measured on the SOCET Set photogrammetric workstation. The difference was determined by subtracting the values of the panel point from the coordinates derived by the San Bernardino County and the USGS static method of survey. The measured panel point values in the stereoimage were roughly parallel to the ground level at an average positional offset of $1.46 \mathrm{~m}$ (delta $\mathrm{x}$ ), -0.27 (delta $\mathrm{y}$ ), and $-0.74 \mathrm{~m}$ (delta vertical). The graph in figure 6 illustrates the comparison of the identified panel point coordinates in the stereoimages against the values of the logged San Bernardino County's surveyed panel coordinates.

A statistical comparison of the difference between the San Bernardino County surveyed panel coordinates and their corresponding panel positions displayed on the digital photogrammetric workstation, in meters, is shown in table 1.

\begin{tabular}{|c|c|c|c|c|}
\hline Ref. & Panel & d_easting & d_northing & d_vertical \\
\hline 1 & 5 & -1.40 & -0.16 & -0.51 \\
\hline 2 & 6 & -1.40 & -0.32 & -0.99 \\
\hline 3 & 8 & -1.63 & 0.00 & 0.41 \\
\hline 4 & 12 & -1.17 & -0.32 & -0.27 \\
\hline 5 & 15 & -1.40 & -0.16 & -1.80 \\
\hline 6 & 16 & -1.63 & -0.32 & -1.60 \\
\hline 7 & 17 & -1.63 & -0.64 & -0.38 \\
\hline \multicolumn{2}{|c|}{ Average } & -1.46 & -0.27 & -0.74 \\
\hline
\end{tabular}

Table1. Difference between the San Bernardino County surveyed panel coordinates and their corresponding panel positions in the stereoimage, in meters

A comparison of the average positional accuracy of the San Bernardino County kinematic-surveyed panel coordinates and their corresponding panel positions in the stereoimages with that of the USGS static-survey panel coordinates for the same panel positions is shown in table 2 . 


\begin{tabular}{|c|r|r|r|}
\hline Crew (survey) & d_easting & d_northing & d_vertical \\
\hline \hline SB Cty (kinematic) & -1.46 & -0.27 & -0.74 \\
\hline USGS (static) & -0.28 & +0.25 & -0.55 \\
\hline
\end{tabular}

Table 2. The average positional accuracy results using the San Bernardino County kinematic survey values in comparison with those of the USGS static survey, in meters.

\section{Summary}

The higher image resolution and the overall positional accuracy of the DSS imagery collected for this study improved considerably in comparison with past tests conducted by the USGS (Sanchez, 2004). Achieving the goal of the $8-15 \mathrm{~cm}$ ( $3-6$ inches) image pixel resolution can be attributed to the faster 2.5 second cycle time of the DSS camera. The more demanding position and height accuracy $(15 \mathrm{~cm}$ or 6 inches) calls for a higher precision of the exterior orientation than was achieved in this project. The multiple reference base station approach using the SCIGN sites did show improvement in the positional accuracy when compared to the single station approach. The average positional offset of the SCIGN multiple reference station approach were $0.28 \mathrm{~m}$ (delta $\mathrm{x}$ ), $0.25 \mathrm{~m}$ (delta y), and $-0.55 \mathrm{~m}$ (delta vertical). By contrast, applying the single base station reference approach showed the average horizontal and vertical positional offset from their true positions as $-2.33 \mathrm{~m}$ (delta $\mathrm{x}$ ), $-1.56 \mathrm{~m}$ (delta y), and $+7.81 \mathrm{~m}$ (delta vertical).

One should note that the positional accuracy assessment in this study was based on the DSS $15-18 \mathrm{~cm}(6-7 \mathrm{inch})$ image pixel dataset collected at a flight height of $1,067 \mathrm{~m}$ $(3,500 \mathrm{ft})$ and not the lower $8 \mathrm{~cm}(3 \mathrm{inch})$ image resolution. Strong cross-winds at $457 \mathrm{~m}$ $(1,500 \mathrm{ft})$ flight altitude resulted in an erratic flight profile and the inability of the pilot to collect $60-80 \%$ overlapping frames required for developing a digital elevation model mosaic of the test area. The POS data showed excessive roll (15 degrees) in the flight mission. "At these magnitudes even a 3-axis mount would not have worked; the only solution would have been to change the flight profile" (Joe Hutton, personal communications, March 26, 2004).

The Applanix airborne integrated digital camera GPS-aided inertial navigation system, together with the network infrastructure provided by the SCIGN, allowed us to perform extraordinarily high-resolution color imaging and achieve reasonably accurate large-scale image mapping in near real time and at very low cost relative to traditional methods. The high informational content and interpretability of the color images enabled us to immediately view scarps, offset channels, and vegetation lineaments along fault traces that go through residential areas. These 1,446 color image files and a background informative readme1st.doc file are available online at http://cortez.gps.caltech.edu/mapsurfer/mapsurfer/mapsurfer.html

This unprecedented spatial resolution permits the pre- and post earthquake mapping of intricacies and complexities of fault slip to help test the dynamic and static strength of 
faults, leading to a vastly improved physical understanding of San Andreas rupture processes, and also vital to post-disaster emergency response in Southern California.

\section{Recommendations}

Although, the position and height results found in this study did not meet the large-scale positional accuracy of less than $15 \mathrm{~cm}$, with proper mission planning, GPS-aided inertial technology has the potential to meet near real-time large scale mapping requirements. Based on the findings of this study and previous studies, the single most important step to achieving the overall positional accuracy required is careful mission planning. Therefore, where the highest GPS position and height accuracy is needed the following recommendations are proposed:

1) Simultaneous collection of data using a combined GPS-aided inertial navigation digital imaging and Lidar system.

2) Conduct boresight tests near the project area before and after the flight mission, and retain results and other calibration information.

3) Design the project to minimize multipath by using closely spaced multiple base stations or a base-line separation of less than $30 \mathrm{~km}$.

4) Operate when six or more satellites are available and PDOP is minimized.

5) Minimize rotation in heavy cross-winds by using a heavier aircraft or changing the flight profile.

6) Minimize cycle slips from occurring by minimizing aircraft bank angles by flying relatively flat turns.

7) After each flight mission check the logged data for gaps, inertial sensor errors, and assure raw GPS observables have no major cycle slips.

8) Retain raw observation data for later evaluation and validation.

\section{Acknowledgments}

The authors would like to thank Katherine Kendrick, USGS-Pasadena, for her participation. Many thanks to Applanix staffers Drew Fisher, Gerald Kinn and field crew who without them this study would not have been possible. Also, thanks to the San Bernardino County Surveyor's Office, in particular, Mike Raihle and Ryan Hunsicker for their cooperation in supplying the aerial panel information, and Fidel Paderes of BAE in San Diego, Calif., for his SOCET Set work-around solutions to software problems. And last but not least, Larry Hothem, USGS-Reston, for his peer review of this paper. This research was funded by the USGS and the National Science Foundation. The aircraft, digital camera and imagery, were donated by Applanix.

\section{References}

Bruton, A. M., Mostafa M. M. R. and Scherzinger B., Airborne DGPS without dedicated base stations for mapping applications, ION-GPS 2001, Salt Lake City, p. 1584-1592. 
Colomina, Ismael, 2000, T.O.P. concepts for sensor orientation, ISPRS 2000, v. 33, Amsterdam.

Cramer, Michael, 1999, Direct geocoding: Is aerial triangulation obsolete; Fritsch/Spiller (eds.), Photographic Week 1999, Heidelberg, Germany, Wichmann Verlag, p. 59-70.

Cramer, M., Stallmann, D. and Haala, N., 2000, Direct georeferencing using GPS/Inertial exterior orientations for photogrammetric applications; International Archives of Photogrammetry and Remote Sensing, v. 33, part B3, p. 198-205.

Hudnut, K. W., Y. Bock, J. E. Galetzka, F. H. Webb, and W. H. Young, 2002, The Southern California Integrated GPS Network (SCIGN), Seismotectonics in Convergent Plate Boundary, Y. Fujinawa and A. Yoshida (Eds.), TERRAPUB, Tokyo, Japan, ISBN 4-88704-129-2, p. 167-189.

Lachapelle, G., 1991, GPS Observables and Error Sources for Kinematic Positioning, Kinematic Systems in Geodesy, Surveying and Remote Sensing, Schwarz, K.P., and Lachapelle G., ed., Springer Verlag, N.Y., 1991, p. 17-26.

Raquet, J.F., 1998, Development of a Method for Kinematic GPS Carrier-Phase Ambiguity Resolution Using Multiple Reference Receivers, UCGE Report 20116. Department of Geomatics Engineering, University of Calgary, Alberta, Canada, p. 259

Sanchez, R.D., and L.D. Hothem, 2002, Positional accuracy of positional accuracy of airborne integrated global positioning and inertial navigation systems for mapping in Glen Canyon, Arizona, U.S. Geological Survey Open-File Report 02-222.

Sanchez, R.D., 2004, Airborne Digital Sensor System and GPS-Aided Inertial Technology for Direct Geopositioning in Rough Terrain, U.S. Geological Survey OpenFile Report 04-151.

Shi, J., 1994, High Accuracy Airborne Differential GPS Positioning Using a MultiReceiver Configuration, UCGE Report 20061, Department of Geomatics Engineering, University of Calgary, Alberta, Canada, p. 129. 